\title{
MULTISCALE AND MULTITEMPORAL URBAN REMOTE SENSING
}

\author{
V. Mesev \\ Department of Geography, Florida State University, Tallahassee, FL 32306, USA - vmesev@fsu.edu
}

Commission II, WG II/2

KEY WORDS: Urban, Scale, Time, Geography

\begin{abstract}
:
The remote sensing of urban areas has received much attention from scientists conducting studies on measuring sprawl, congestion, pollution, poverty, and environmental encroachment. Yet much of the research is case and data-specific where results are greatly influenced by prevailing local conditions. There seems to be a lack of epistemological links between remote sensing and conventional theoretical urban geography; in other words, an oversight for the appreciation of how urban theory fuels urban change and how urban change is measured by remotely sensed data. This paper explores basic urban theories such as centrality, mobility, materiality, nature, public space, consumption, segregation and exclusion, and how they can be measured by remote sensing sources. In particular, the link between structure (tangible objects) and function (intangible or immaterial behavior) is addressed as the theory that supports the wellknow contrast between land cover and land use classification from remotely sensed data. The paper then couches these urban theories and contributions from urban remote sensing within two analytical fields. The first is the search for an "appropriate” spatial scale of analysis, which is conveniently divided between micro and macro urban remote sensing for measuring urban structure, understanding urban processes, and perhaps contributions to urban theory at a variety of scales of analysis. The second is on the existence of a temporal lag between materiality of urban objects and the planning process that approved their construction, specifically how time-dependence in urban structural-functional models produce temporal lags that alter the causal links between societal and political functional demands and structural ramifications.
\end{abstract}

\section{INTRODUCTION}

An urban subfield of remote sensing has organized and matured rapidly over the last twenty years. Most of the impetus can be attributed to the availability of fine scale sensor data from satellites such as Ikonos, Quickbird and GeoEye. These and information from traditional aerial photography facilitate statistical techniques that measure the geometric dimensions of urban features. Output has included the creation and updating of large-scale urban land use/ land cover maps, as well as indicators of sprawl, the magnitude of heat islands, generalized poverty maps, and data for models designed to alleviate traffic congestion. All have taken advantage of the innate benefits of remote sensing-their instant availability, and spectral, multiscale and multitemporal multidimensionality.

However, far less attention has been bestowed to research that embraces the basic, core theories that have built the more substantive field of urban geography (Whitehand, 1977). Surely if urban remote sensing is to develop and mature into a scholastically respected and epistemologically rigorous discipline it cannot afford to ignore the theories that it aims to measure. Theories, such as centrality, mobility, materiality, nature, public space, consumption, segregation and exclusion are pivotal to understanding urban history, evolution, current configuration and future possibilities. Pragmatically, all these core urban theories essentially represent the link between structure (tangible objects) and function (intangible, immaterial behavior), which in turn defines the well-know contrast between land cover and land use classification from remotely sensed data. This structural-functional relationship can be explored by two analytical fields. The first is the search for an appropriate spatial scale of analysis; the second on the appreciation of a temporal lag between materiality of urban objects and the planning process that approved their construction-specifically how time-dependence in urban structural-functional models produce temporal lags that alter the causal links between societal and political functional demands and structural ramifications. For research that address these spatial and temporal issues consult, Brenner (2000), Couloigner and Ranchin (2000), Longley (2002), and Gamba et al. (2005).

\section{MICRO VERSUS MACRO URBAN REMOTE SENSING}

The premise of scale as a dictating factor in urban remote sensing has not attracted as much attention from the research community as Welch's seminal work in 1982 deserved. This is in contrast to technological improvements in sensor engineering which has led to the availability of image data at finer spatial resolutions. Perhaps the question lies more with the scale of analysis rather than the spatial resolution of the sensor data. Surely choosing the sensor data at the 'appropriate' spatial resolution should be inextricably linked to their use-the range of the application. For urban studies this equates to finding a consistent match between the spatial resolution of remote sensor data and their most appropriate urban application. This may sound an overly simplistic and intuitive prerequisite, but determining this data-to-application condition requires a number of considerations. These can be categorized into two groups, one dealing with the measurement of tangible urban structures and features at the micro scale of analysis, and the other dealing with the functionality of urban movements and processes at the macro scale of analysis. Synchronizing 
these two groups is key to choosing a scale of remote sensing analysis that is most appropriate for measuring the urban structural-functional relationship-and in turn understanding processes and eventually fine-tuning theory.

Originally, urban remote sensing research was expected to benefit from both micro and macro scales of analysis when higher spatial resolution satellite sensor data (IKONOS, QuickBird, GeoEye) first became available. However, to date, the level of expectation for these high spatial resolution satellite sensor datasets seems to have exceeded the number of practical urban applications. Despite the perceived advances in clarity and detail stemming from pixels representing smaller instantaneous fields of view, most of the criticism, paradoxically, has been linked with the increased spectral heterogeneity resulting from the finer scaled spatial resolution. It means that urban classifications remain highly tenuous and any reliable micro remote sensing, usually in the form of precision mapping, is extracted either directly from the spatial orientation of pixels - in the similar vein to conventional interpretation of aerial photography, but with slightly lower clarity and without stereoscopic capabilities — or with the aid of disaggregate ancillary data from postal records, population censuses, or planning sources. Figure 1a illustrates the exceptionally high level of detail from a digital aerial photograph at the unprecedented spatial scale of $12 \mathrm{~cm}$ which inevitably produces many information classes. The area is of a small geographic section of the city of Belfast in the United Kingdom.

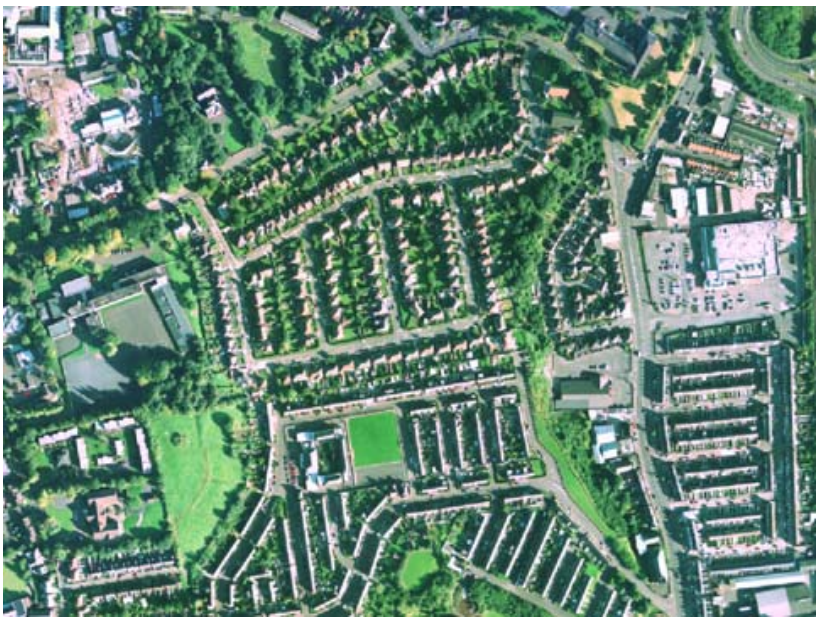

Figure 1a: Micro urban remote sensing.

Digital aerial photography at a spatial resolution of $12 \mathrm{~cm}$ (Belfast, UK).

In contrast, the spectral heterogeneity factor is less of a restriction for macro remote sensing, which is more concerned with a generalized view of an urban area such as neighborhoods, zones or even the whole city. Classification accuracy is also less important; the emphasis shifting towards interpreting generalized land cover/ land use, measuring overall building density, and understanding urban processes such as growth, congestion/pollution, and deprivation. Arguably, it is this understanding of urban processes that many researchers consider more important for understanding complete urban theories that drive growth, density, and even poverty and sustainability. However, to fully appreciate the scale of dynamic urban changes remotely sensed data need to be embellished with ancillary information measuring socioeconomic characteristics, housing descriptors, and zoning restrictions. Figure 1b illustrates macro urban remote sensing where a standard dasymetric analysis between Landsat TM and a population census has generated an average household size map at the tract level for the whole city of Bristol in the United Kingdom.

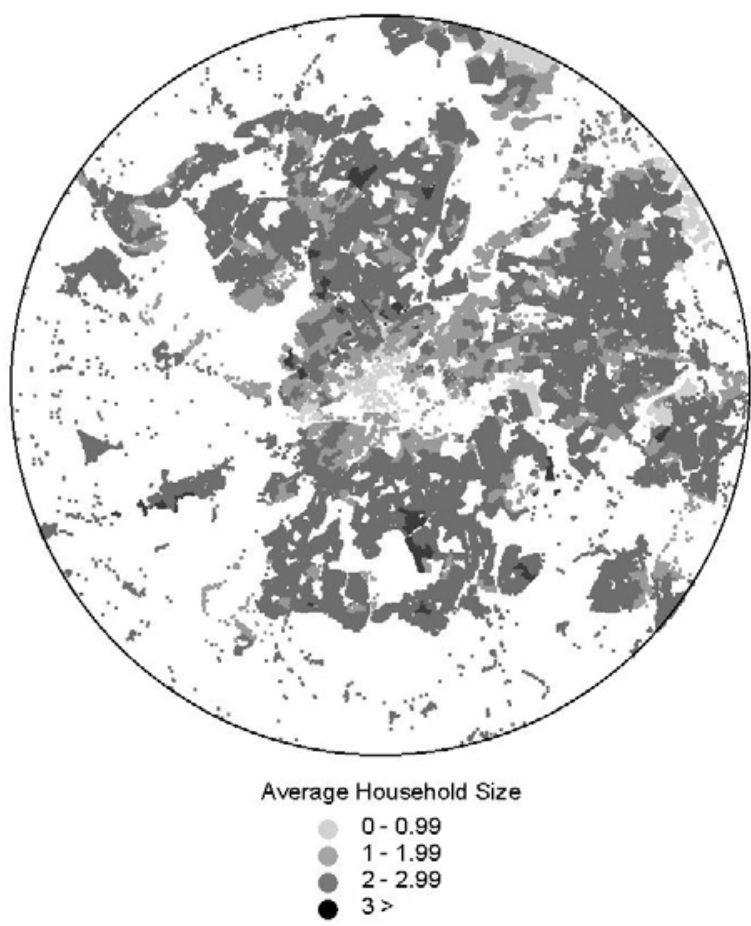

Figure 1b: Macro remote sensing.

Landsat TM image classified into residential land use and linked by dasymetric mapping to population census to calculate average household size (Bristol, UK).

\section{CHOOSING THE 'APPROPRIATE' SCALE OF ANALYSIS}

The search for the 'appropriate' scale of analysis requires a research agenda that links the statistical measurement of urban structure from remotely sensed data with theoretical underpinnings of urban function across not only spatial scales but also temporal intervals. In empirical terms, this is tantamount to developing sensitivity analyses of remotely sensed data at various spatio-temporal resolutions, linking them with functional data, and then comparing their accuracy levels.

These are the so-called spatio-temporal structural-functional models and examples include high spatial resolution sensor images to measure urban structure, and point-based mailing addresses and rasterized area-based census surfaces to tessellate socioeconomic characteristics of urban areas (Figures 2 and 3). The spatio-temporal models also reject the widespread 
assumption of the static city, especially when remotely sensed data are linked with such ancillary information. What is needed is a theoretical basis from which to interpret and understand urban land cover and land use change; particularly the concept of a temporal lag between what an urban society demands and what urban physical consequences materialize.
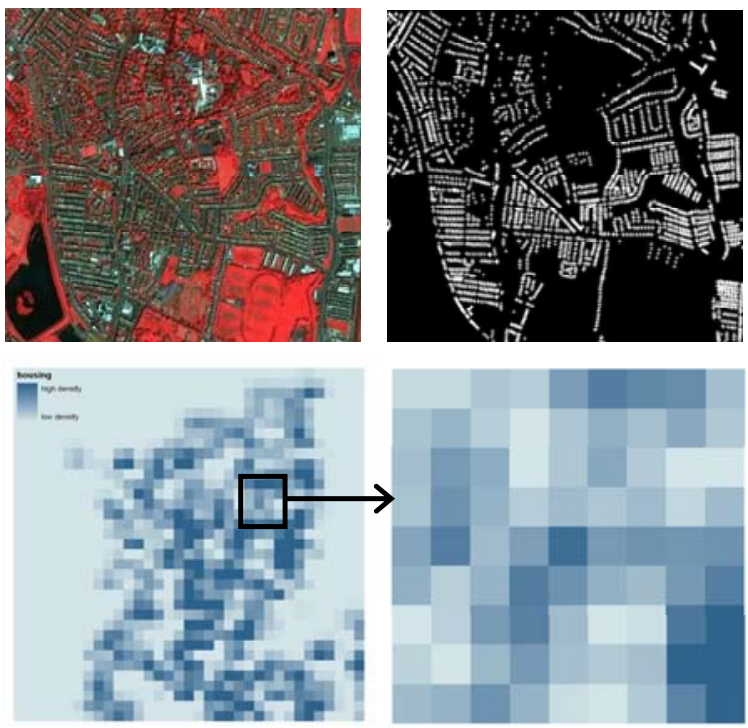

Figure 2: Structural and functional representations of the city of Belfast U.K. IKONOS image (top left), postal addresses (top right), census housing surface (bottom left, for whole of NE Belfast; bottom right, the same spatial dimensions as IKONOS image and postal addresses).

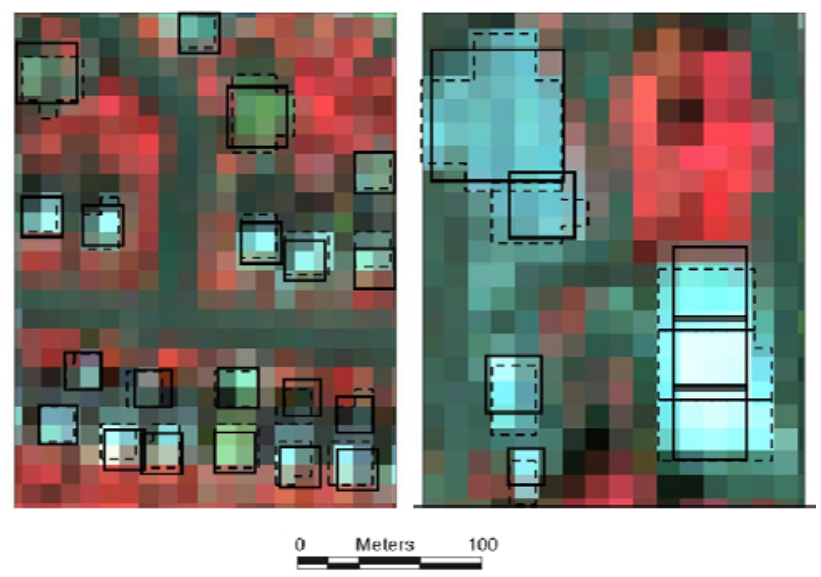

Figure 3: Structural-functional model. IKONOS image representing urban residential structure (left) and urban commercial structure (right). Postal data (POINTER database in the UK) using the area variable to represent residential function (left) and commercial function (right).

\section{TEMPORAL LAG IN URBAN REMOTE SENSING}

A more recent perspective on research into urban structuralfunctional models is the pursuit of time-dependence; understanding how temporal lags affect the causal links between societal and political functional demands and physical ramifications. Thus far integrative remote sensor models have assumed temporal equality. This is where the same time period is assumed for both when the image was taken and when functional attributes are collected. Instead, a temporal integrative model is built at two time periods ( $T_{1}$ and $T_{2}$ ) formulated by combining urban structural patterns (derived from classified remote sensor data) post $T_{1}$ as $T_{1+1}$ and post $T_{2}$ as $T_{2+1}$ and urban functional demands and decisions (derived predominantly from population censuses and urban plans) pre $T_{1}$ as $T_{1-1}$ and pre $T_{2}$ as $T_{2-1}$ respectively.

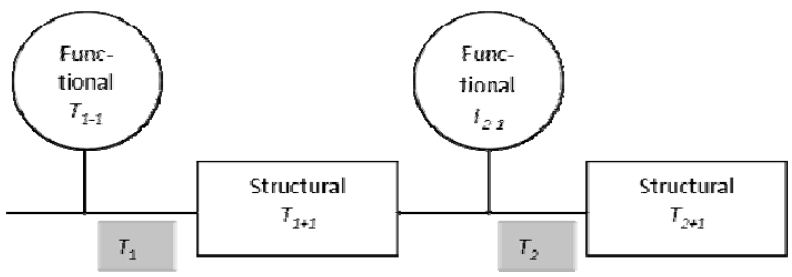

The relationship states that decisions and trends in urban functions at T1-1 determine the type and density of urban structure at T2-1. Investigation of theory in urban geography, how it relates to urban remote sensing and the micro/macro and temporal lag issues are critical for developing complete views of complex cities, and help us understand urban dynamics in a robust, up to date, and holistic manner.

\section{EMPIRICAL MEASUREMENT OF TEMPORAL LAGS}

There a variety of conceivable methods to determine and even measure temporal lags between structure and function. These can be data-driven, process-driven, or theory-driven. The review by Lo (2007) investigated the development of geospatial technology and its use and potential use in urban morphology. The fields of remote sensing, photogrammetry and GIS when combined are particularly important and suitable for use in urban morphological research. Among the many data-driven applications based on these geospatial technologies, Taubenbock et al. (2009), in particular, explored the benefits of multitemporal remote sensing for analyzing long-term changes in temporal and spatial urban sprawl, redensification and urban development for large cities in India. Most other studies also develop analytical models to simulate and evaluate temporal changes. Benguigui et al. (2004) investigated the temporal lag of towns in the Tel Aviv area by comparing an analytic model with a computer simulation to predict population growth. In the dynamic analytic model they used time in two phase; in the first, the derivative was an increasing function-a town was very attractive and there was a short delay between decision to build and complete realization of the process-and there was no shortage of land. However in the other time phase the delay began to increase and there was a lack of available land, leading to a decreased the rate of the population variation until saturation.

Cheng and Masser (2004) acknowledged the inherent spatial and temporal complexity of urban growth by developing a 
process-oriented cellular automata methodology at both the local spatial and the global dynamic scales based planning and decision-making processes. They linked spatial and temporal patterns using an innovative nonlinear function of land development and dynamic weighting. The model approach was more recently developed by Chen (2009) who investigated spatial interactions between cities based on a time-lag parameter and time functions, and developed a Newtonian-type model that integrated a temporal dimension into the spatial processes of city distributions. In terms of theory-driven work, Dietzel et al. (2005) attempted to develop theories in spatiotemporal dynamics urban geography by using remotely sensed data to determine the historical extent of urban areas and spatial metrics patterns of urban growth over a hundred year period. Changes in these metrics produced a general temporal oscillation between phases of diffusion and coalescence in urban growth. In more abstract terms, Latham and McCormack (2004) postulated that any increased attention to the 'material' requires a more expansive engagement with the 'immaterial' when attempting to understand the complex spatialities of the urban. And finally, Aubrecht et al. (2009) developed an integrative model of three-dimensional urban structure and function centered on airborne laser scanning, geocoded address point data and raster population surface producing accurate functional classifications.

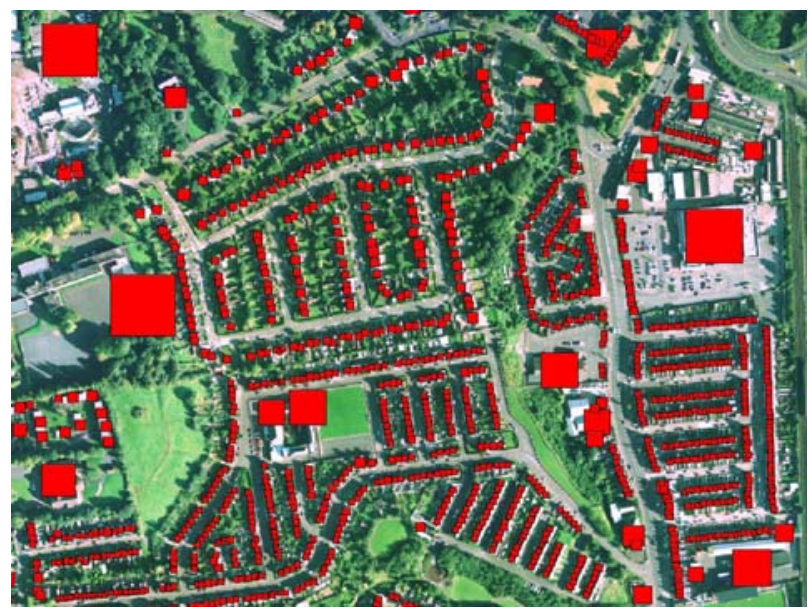

Figure 4: Temporal structural-functional model. Aerial photograph represents the urban structure of Belfast, UK in $2010\left(T_{2}\right)$, while postal data (POINTER database) represents residential function of the same area in $2000\left(T_{1}\right)$.

In summarizing the literature on urban temporal lags, it seems research is either on-going or in theoretical development. Any models dealing in any all or some combination of urban temporality, structuralism, and functionality have or are currently being designed to create more complete representations of urban morphology and socio-economic characteristics, where temporal lags are non-linear indicators of land cover/ land use changes. Current work outlined by the author in this chapter is at a similar prototype stage and sensitivity analyses are presently being developed to determine the concept of the optimum temporal lag, i.e. whether it should be decennial to coincide with most population censuses or inter-decennial. Research is underway to establish whether such integrative and dynamic models have also the ability to predict urban growth based on the relationship between land cover/ land use (as measured by remotely sensed data) and population and demographic demands (as measured by the census and other socioeconomic and housing sources). It is hoped in the fullness of time that such models of temporality will become vital components in the monitoring of city-wide variations of social deprivation, housing density, traffic congestion, heat island effects, non-point source pollution and others issues of urban sustainability.

In the meantime, temporal lags may be observed without the need for an analytical model. Figure 5 illustrates a simple spatial comparison between point-based POINTER (successor to COMPAS) data from 2007 with an Ikonos image taken in May 2009. Even with a two-year difference, there is evidence (in the top middle section of the figure) of a temporal lag. This is where the pixels from the Ikonos image clearly show spectral colors associated with new built land cover yet the POINTER dataset has yet to be updated. This is obviously a situation of temporal discrepancy and the real question is whether such new structural developments in urban areas can be linked by functional demand by the population and if they can be linked whether they are predictive of future urban development. These are issues that need further research.

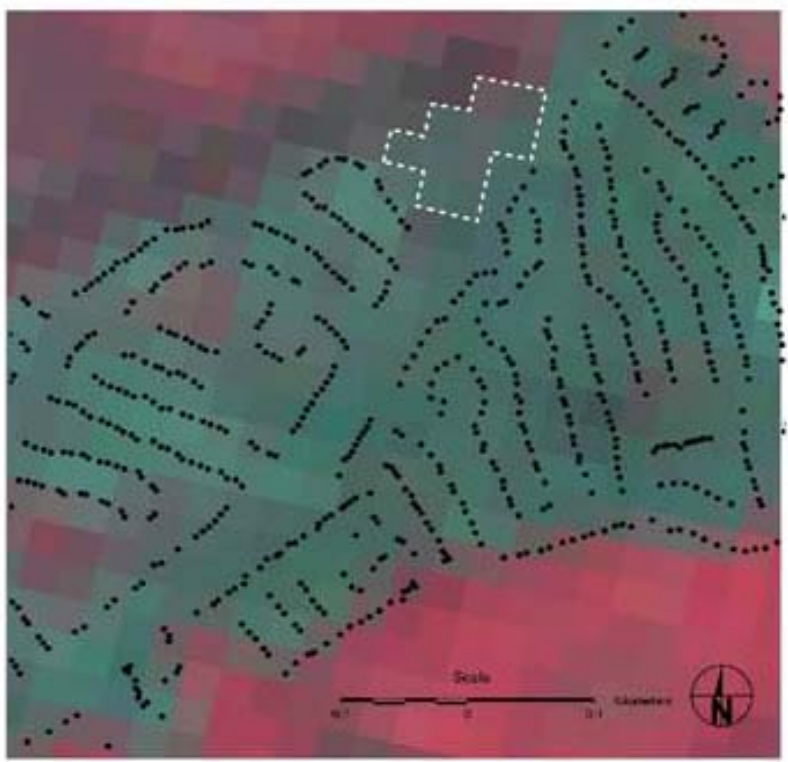

Figure 5: Evidence of a temporal lag between structure and function. Area highlighted in white represents structural residential land use (from IKONOS sensor image) yet

functional representation (by postal records) has not been updated for the city of Bristol, UK.

\section{CONCLUSIONS}

Precisely how urban functions determine urban structure (and maybe even how structure determines functions) is reflective of theories of urban process; for instance, demand for new housing type and housing density, suburbanization, decentralization of businesses, segregation levels, deprivation and congestion, heat island effects, non-point source pollution 
and others issues of urban sustainability. Research should be aimed at developing models to predict urban growth based on previous demands and policies for new residential and commercial developments. Moreover, scientists engaged in urban remote sensing research to advocate models and methodologies that are more pragmatic and prescriptive; with the distinct objective of informing policy makers of possible demands for residential development and commercial expansion. And finally, the challenge is to stimulate conceptual thinking of how temporal lags help define prescriptive methodologies that help target possible changes in urban structure with careful reference to population censuses that were taken well before these structural changes materialized.

Urban remote sensing is gaining in prominence on the world stage yet has far to go before being able to foster rigorous and reliable models of the urban hierarchy - the most spatially diffuse and functionally dynamic landscapes on the earth's surface. The distinction between micro and macro remote sensing equates to a distinction between precision urban structural (syntactic) configuration and city-wide functional representation using integrative models that link spectral information from high spatial resolution sensor data with spatial and temporal indicators from auxiliary sources. In each the focus is on integrative models that explore metrics and maximization procedures in an attempt to summarize the cartographic and geocomputation potential of the burgeoning urban remote sensing technology.

\section{REFERENCES}

Aubrecht, C., Steinnocher, K., Hollaus, M. and Wagner, W., 2009. Integrating earth observation and GIScience for high resolution spatial and functional modeling of urban land use. Computers, Environment and Urban Systems, 33:15-25.

Benguigui, L., Czamanski, D. and Marinov, M., 2004. Scaling and urban growth. International Journal of Modern Physics C, 15(7):989-996.

Brenner, N., 2000. The urban question as a scale question: reflections on Henri Lefebvre, urban theory and politics of scale. International Journal of Urban and Regional Research, 24(2):361-378.

Chen, Y.G., 2009. Urban gravity model based on crosscorrelation function and Fourier analyses of spatio-temporal process. Chaos Solutions and Fractals, 41(2):603-614.

Cheng, J. and Masser, I., 2004. Understanding spatial and temporal processes of urban growth: cellular automata modelling. Environment and Planning B, 31:167-194.

Couloigner, I. and Ranchin, T., 2000. Mapping of urban areas: A multiresolution modeling approach for semi-automatic extraction of streets. Photogrammetric Engineering and Remote Sensing, 66:867-874.

Dietzel, C., Herold, M., Hemphill, J.J. and Clarke, K.C., 2005. Spatio-temporal dynamics in California's central valley: empirical links to urban theory. International Journal of Geographical Information Science, 19(2):175-195.

Gamba, P., Dell'Acqua, F. and Dasarathy, B.V., 2005. Urban remote sensing using multiple data sets: past, present, and future. Information Fusion, 6, 319-326.

Latham, A. and McCormack, D.P., 2004. Moving cities: rethinking the materialities of urban geography, Progress in Human Geography, 28(6):701-724.

Lo, C.P., 2007. The application of geospatial technology to urban morphological research. Urban Morphology, 11(2):8190.

Longley, P.A., 2002. Geographical information systems: will developments in urban remote sensing and GIS lead to 'better' urban geography? Progress in Human Geography, 26:231-239.

Mesev, V., 2003. Remotely Sensed Cities. Taylor \& Francis, London.

Taubenbock, H., Wegmann, M., Roth, A., Mehl, H. and Dech, S., 2009. Urbanization in India - spatiotemporal analysis using remote sensing data. Computers, Environment and Urban Systems, 33(3):179-188.

Welch, R., 1982. Spatial resolution for urban studies. International Journal of Remote Sensing, 3(2):139-146.

Whitehand, J.W.R., 1977. The basis for an historicogeographical theory of urban form. Transactions of the Institute of British Geographers, 2(3):400-416. 